\title{
IN VITRO ANTIDIABETIC EFFECTS OF FERULA ASSA-FOETIDA EXTRACTS THROUGH DIPEPTIDYL PEPTIDASE IV AND $\alpha$-GLUCOSIDASE INHIBITORY ACTIVITY
}

\author{
ADEL YARIZADE ${ }^{1}$, HASAN HASANI KUMLEH ${ }^{1}$, ALI NIAZI ${ }^{2 *}$ \\ ${ }^{1}$ Department of Plant Biotechnology, Faculty of Agriculture, University of Guilan, Rasht, Iran. ${ }^{2}$ Institute of Biotechnology, \\ Shiraz University, Shiraz, Iran. Email: niazi@shirazu.ac.ir
}

Received: 16 December 2016, Revised and Accepted: 01 March 2017

\section{ABSTRACT}

Objective: Diabetes mellitus (DM) causes hyperglycemia, which is one of the most common diseases in the world. One of the strategies for the treatment of diabetes is maintaining postprandial glucose level through inhibition of dipeptidyl peptidase IV (DPP-IV) and $\alpha$-glucosidase enzymes. The aim of this study was to determine in vitro antidiabetic potential of Ferula assa-foetida via DPP-IV and $\alpha$-glucosidase inhibitory activities.

Methods: F. assa-foetida seeds were extracted in methanol, ethanol, ethanol-methanol, and water. Inhibitory activity on DPP-IV and $\alpha$-glucosidase was performed in vitro and measured spectrophotometrically at $\lambda=405 \mathrm{~nm}$.

Results: The result showed that the F. assa-foetida seed extract is effective against both enzymes. All fractions had DPP-IV inhibitory activity, but the ethanolic fraction had the highest inhibitory activity on DPP-IV enzyme and significantly decreased DPP-IV activity (24.5\%). With respect to $\alpha$-glucosidase inhibitory activity, the aqueous extract has the highest inhibitory activity (28\%).

Conclusion: According to the results of this study, F. assa-foetida contains DPP-IV and $\alpha$-glucosidase inhibitors and could be a potential source for the discovery of active constituents as $\alpha$-glucosidase and DPP-IV inhibitors to treat Type 2 DM.

Keywords: Diabetes mellitus, Herbal medicine, Dipeptidyl peptidase IV, $\alpha$-glucosidase.

(C) 2017 The Authors. Published by Innovare Academic Sciences Pvt Ltd. This is an open access article under the CC BY license (http://creativecommons. org/licenses/by/4. 0/) DOI: http://dx.doi.org/10.22159/ajpcr.2017.v10i5.16648

\section{INTRODUCTION}

Diabetes mellitus (DM) is a group of metabolic disorders in which the body cannot effectively use the insulin, has defects in insulin secretion or both, that lead to high blood glucose. Type 2 DM (T2DM) is the most common type of this disease and accounts for at least $90 \%$ of all cases of diabetes [1]. Although in most patients with T2DM, there may be no obvious symptoms for a long period, it still threatens human health. Blurred vision, drowsiness, weight gain, numbness in hands and feet, and gum disease are some symptoms of T2DM in patient [2].

The incidence of T2DM is rising dramatically worldwide. According to the International Diabetes Federation, 425 million people are affected by diabetes worldwide, every 6 seconds one person dies from diabetes with 5 million deaths reported in 2015 and diabetes expenditure reached USD 1.197 billion [3].

At first, T2DM can be managed by lifestyle changes that include diet and exercise, but due to the progressive nature of this disease, exercise and proper diet may not completely solve the problem so oral hypoglycemic drugs are necessary to treat T2DM. Insulin therapy is the most effective treatment, generally used in advanced stages of T2DM when other therapeutic strategies are no longer effective [4-6].

Based on the pathogenic mechanisms of T2DM, various medications have been produced and are prescribed for patients according to symptoms of disease. $\alpha$-glucosidase inhibition is one of the mechanisms of action of these medications. $\alpha$-glucosidase plays a role in the conversion of carbohydrates into glucose. By inhibiting $\alpha$-glucosidase, glucose levels in the blood can be returned to normal limits. Hence, use of pharmaceuticals that inhibit activity of this digestive enzyme could be a good treatment for T2DM. The most recent medications used to treat T2DM are inhibitors of dipeptidyl peptidase IV (DPP-IV). DPP-IV rapidly destroys the incretin hormones, glucagon-like peptide-1 (GLP-1) and gastric inhibitory polypeptide (GIP). These peptides are members of the glucagon peptide superfamily that helps the body produce more insulin when it is needed [1,7-11].

Nowadays, several DPP-IV inhibitors are available that can be taken orally in tablet form. Synthetic oral hypoglycemic drugs are the most common form of treatment for T2DM, but they have undesirable side effects in patients with T2DM [4]. Moreover, these drugs impose a high cost to patients and sometimes, especially in developing countries, the majority of patients cannot afford the high cost of the drugs. Therefore, research on medicinal plants as inexpensive resources containing valuable pharmaceutical metabolites and identification of drugs with high efficiency and lower side effects is essential.

Ferula assa-foetida L. is an important medicinal plant belonging to the Apiaceae family with many medicinal benefits. "Asafoetida" derived from the Persian word "asa" (resin) and Latin foetida that means "odorous," refers to its strong sulfurous odor.

According to the literatures, this herbaceous perennial plant is found in central Asia, Iran to Afghanistan, from which it is exported to the entire world. Traditionally, it is used for the treatment of different diseases, such as stomach ache, asthma, epilepsy, flatulence, weak digestion, intestinal parasites and influenza [12]. Recent pharmacological and biological studies have also shown several activities, such as antioxidant [13], antiviral [14], antimicrobial [15], antispasmodic and hypotensive [16], and antidiabetic [5,17].

Nowadays identification of more efficient pharmaceuticals with less side effects and understanding the mechanism of action of hypoglycemic activity of medicinal plants is an important matter. Since the antidiabetic effects of $F$ assa-foetida L. have been proven in in vivo 
studies, but the exact mechanism(s) of blood glucose-lowering effect of this herb is not well-known, so this study was carried out to investigate the $\alpha$-glucosidase and DPP-IV inhibitory activities of Ferula asafetida L. as two of the most important hypoglycemic mechanisms.

\section{MATERIAL AND METHODS}

\section{Chemicals}

DPP-IV from porcine kidney, Gly-Pro p-nitroanilide p-toluenesulfonate, $\alpha$-glucosidase from Saccharomyces cerevisiae, 4-nitrophenyl $\alpha$-Dglucopyranoside, and Acarbose purchased from Sigma. All other chemicals used for the experiment were of analytical grade.

\section{Sample preparation}

The F. assa-foetida seeds were collected and then powdered using grinder. $25 \mathrm{~g}$ of powdered plant seed were extracted with $50 \mathrm{ml}$ methanol, ethanol, methanol-ethanol and water on an orbital shaker for $24 \mathrm{hrs}$. The resulting extracts were filtered using Whatman No. 1 filter paper to remove plant debris, and the filtrate was allowed to dry under a stream of air at room temperature. Dried extracts were weighed and dissolved in dimethylsulphoxide to yield a stock solution. The solution was stored at $4^{\circ} \mathrm{C}$ for subsequent use.

\section{$\alpha$-glucosidase inhibitory activity assay}

The $\alpha$-glucosidase inhibition was determined using the modified method according to Ooi et al. [18]. In brief, the reaction mixture contained 50 $\mathrm{mM}$ 4-nitrophenyl $\alpha$-D-glucopyranoside as substrate, $50 \mu \mathrm{L}$ of the extract $(0.5 \mathrm{mg} / \mathrm{ml})$ or Acarbose (positive control) and $50 \mu \mathrm{l}$ of $\alpha$-glucosidase $(0.05 \mathrm{U} / \mathrm{ml})$ and $50 \mu \mathrm{l}$ sodium phosphate buffer $(0.1 \mathrm{mM}, \mathrm{pH} 6.9)$ were incubated at $30^{\circ} \mathrm{C}$ for 40 minutes. Then, the reaction was terminated by the addition of $100 \mu \mathrm{l}$ of $0.2 \mathrm{M}$ sodium carbonate solution and absorbance was determined at $405 \mathrm{~nm}$ using plate reader.

$\alpha$-glucosidase inhibitory activity was determined as follows:

$$
\% \text { Inhibition }=\frac{\alpha \text {-glucosidase activity with extract }}{\alpha \text {-glucosidase activity without extract }} \times 100
$$

\section{DPP-IV inhibitory activity assay}

DPP-IV inhibitory activity assay was performed colorimetrically using Gly-Pro p-nitroanilide p-toluenesulfonate as chromogenic substratein triplicate following the modified method of Matheeussen et al. [19]. DPP-IV cleaves the chromogenic substratetorelease the yellow colored product measured at $405 \mathrm{~nm}$. Briefly, in a 96-well plate, DPP-IV inhibition test was conducted with the following conditions: $50 \mu \mathrm{L}$ of various extract $(0.5 \mathrm{mg} / \mathrm{ml})$ and $50 \mu \mathrm{L}$ of DPP-IV enzyme $(0.01 \mathrm{u} / \mathrm{ml})$ were added to each well, pre-incubated at $37^{\circ} \mathrm{C}$ for 10 minutes, then $25 \mu \mathrm{L}$ of the substrate $(1.5 \mathrm{mM})$ was added to the mixture bringing the final volume to $200 \mu \mathrm{L}$ with Tris buffer $\mathrm{pH}=8$, incubated at $37^{\circ} \mathrm{C}$ and the reaction was stopped after $1 \mathrm{hr}$ by adding $100 \mathrm{ml}$ of sodium acetate $\mathrm{pH}=4$. Absorbance was taken at $405 \mathrm{~nm}$ by ELx808LBS Absorbance Plate Reader (Bio-TEK, USA).

The results obtained were compared with the negative control (no inhibitor).

Percentage of inhibition was calculated by the following formula:

$$
\% \text { Inhibition }=\frac{\text { DPP }- \text { IV activity with extract }}{\text { DPP }- \text { IV activity without extract }} \times 100
$$

\section{RESULTS AND DISCUSSION}

\section{$\alpha$-glucosidase inhibitory activity assay}

Inhibition of the $\alpha$-glucosidase that retards the liberation of glucose from dietary complex carbohydrates is one of the important methods to delay the absorption of glucose from the digestive system. Nowadays, one group of drugs that is used to treat T2DM are this kind of inhibitors, but due to the cost of synthetic drugs and their side effects, finding more efficient and safer drugs is crucial. Therefore, the use of herbs as alternative medicine as well as to find valuable pharmaceutical metabolites has significant value, especially for the treatment of diabetes. In this study, the results of the $\alpha$-glucosidase inhibitory activity assay showed that aqueous extract of Asafoetida seed had strong inhibitory activity (Table 1), and this inhibitory activity was concentration-dependent. So that by increasing the concentration of extract from 0.1 to $1 \mathrm{mg} / \mathrm{L}$, the inhibitory activity increased dramatically from $10 \%$ to $40 \%$ (Fig. 1).

Although it has long been proven that assa-foetida has anti-diabetic activity, the glucose-lowering mechanisms of this plant are not clearly known. When streptozotocin-induced diabetic rats were treated with the Asafoetida extract at a dose of $50 \mathrm{mg} / \mathrm{kg}$, the serum glucose concentration decreased significantly in comparison with untreated diabetic rats [20]. Hence, one possible reason for the decreased blood glucose level caused by Asafoetida extract in streptozotocin-induced diabetic rats could be due to having inhibitory effect on glucosidase enzyme activity. Because our result showed that Asafoetida has inhibitory effect on this enzyme.

In another study to find out the mechanisms of the blood glucose lowering action of assa-foetida, the glucose transporter type 4 (GLUT4) was studied in $\mathrm{C} 2 \mathrm{C} 12$ cell. Data indicated that assa-foetida treatment increases translocation of the GLUT4 to the cell membrane which may be one of the possible mechanisms of antihyperglycemic effect of assafoetida [21].

According to our results, $\alpha$-glucosidase inhibition is one of the main mechanisms of antihyperglycemic activity of Asafoetida and thereby reduces blood glucose.

Several studies have been conducted to evaluate $\alpha$-glucosidase inhibitory activity of medicinal plants as an important antidiabetic factor. For instance, Hasimun et al. evaluated $\alpha$-glucosidase inhibitory activity of Zingiberaceae family and found that selected members of this family Hada varied range of IC50 from $28.4 \mu \mathrm{g} / \mathrm{ml}$ to $269.2 \mu \mathrm{g} / \mathrm{ml}$ against $\alpha$-glucosidase. So concluded that the Zingiberaceae family has good potential for use as an alternative medicine to treat DM [22]

Table 1: Percent reduction in $\alpha$-glucosidase enzyme activity by different extracts of $F$. assa-foetida seed

\begin{tabular}{ll}
\hline Extracts & $\begin{array}{l}\text { Percentage of } \boldsymbol{\alpha} \text {-glucosidase inhibitory } \\
\text { activity }(\%)\end{array}$ \\
\hline Ethanol & $14.627 \pm 0.707$ \\
Methanol & $14.860 \pm 1.092$ \\
Ethanol-methanol & $7.40 \pm 7.01$ \\
Aqueous & $28.21 \pm 2.63$ \\
\hline
\end{tabular}

F. assa-foetida: Ferula assa-foetida

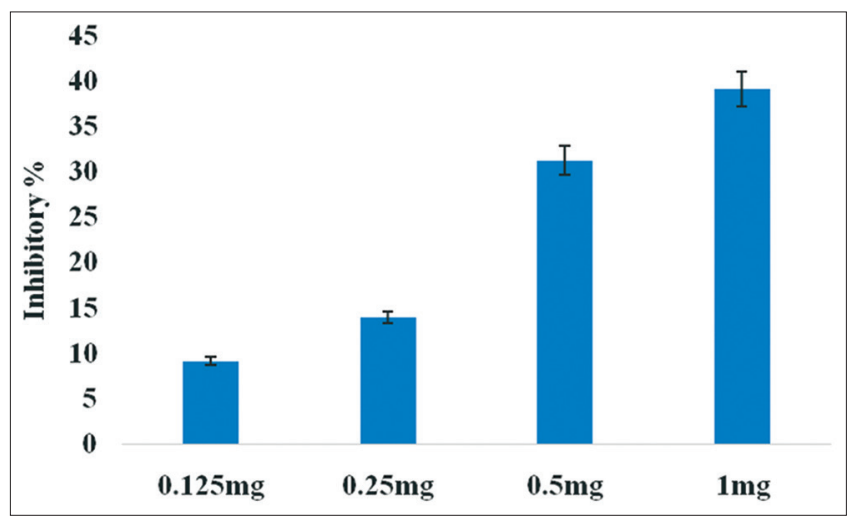

Fig. 1: $\alpha$-glucosidase inhibitory activity of different concentrations of aqueous extract of Ferula assa-foetida seed 
Furthermore, $\alpha$-glucosidase inhibitory activity of Abutilon indicum was investigated and IC50 of the A. indicum methanolic leaf extract on $\alpha$-glucosidase was $137.61 \mu \mathrm{g} / \mathrm{ml}$ indicates that this plant has good potential antidiabetic activity [23].

\section{DPP-IV inhibitory activity}

This approach is the latest treatment method to deal with T2DM, including inhibition of DPP-IV enzyme that breaks down GLP-1, the insulin secretion stimulating peptides, and reduces its half-life to just under 2 minutes. Due to the disadvantages mentioned on chemical medicines and the benefits of herbs and natural metabolites, assafoetida was studied to identify the possible mechanisms of antidiabetic activity. Results showed that all four fractions of methanolic, ethanolic, methanol-ethanolic and water extract had DPP-IV inhibitory properties, but it is noteworthy that ethanolic and ethanol-methanolic fractions had the highest inhibitory activity and aqueous fraction showed the lowest inhibition activity (Table 2)

According to the results of this study, assa-foetida probably reduces blood glucose by inhibiting $\alpha$-glucosidase and DPP-IV activity, leading to reduce glucose absorption from the digestive system and stimulating the production of insulin by increasing the half-life of GLP-1, respectively. The results of some in vivo studies showed that the use of Asafoetida increases the amount of insulin in diabetic mice.

Yusufoglu suggested that the antihyperglycemic effects of assa-foetida could be due to its insulin-secreting activity. Administration of $F$. assafoetida (200 and $400 \mathrm{mg} / \mathrm{kg}$ ) extract to diabetic rats increased the levels of insulin compared to the diabetic control rats [17]. Forasmuch as GLP-1 has a potent effect on insulin secretion so when the GLP-1degrading enzyme is inhibited (DPP-IV) by an inhibitor, the level of GLP-1 will increase and induces insulin secretion and finally the blood glucose decreases.

The effectiveness of medicinal plants in reducing blood glucose and increasing plasma insulin levels has been proven in many studies.

Feeding the streptozotocin-induced diabetic rats with the powdered Du-zhong (Eucommia ulmoides Oliv.) leaves and its aqueous extract for 3 weeks based on $1 \%$ dried Du-zhong leaves, reduced plasma glucose occurred simultaneously with the increase in plasma insulin [24].

To evaluate antidiabetic effect of Caulerpa lentillifera, the inhibitory effect of $C$. lentillifera extract on DPP-IV and $\alpha$-glucosidase activity was measured in a cell-free system. Results showed that $C$. lentillifera extract significantly decreased DPP-IV and $\alpha$-glucosidase activities and, therefore, C. lentillifera could be used as a potential anti-diabetic agent [25].

Methanolic leaf extract of Mangifera indica [26], hexane extract of Annona squamosal [27], the ethanolic extract of Urena lobate [28], and the aqueous leaves extract of Cistus incanus L. [29] is some studies that have inhibited DPP-IV enzymatic activity. The level of plasma GLP-1 in rats treated with the polar fraction of Pueraria tuberosa was increased that it was due to the inhibitory effects on DPP-IV enzyme [30].

\section{CONCLUSION}

T2DM is the most common type of diabetes. Symptoms such as blurred vision, drowsiness, weight gain, numbness in hands and feet, and gum

Table 2: DPP-IV inhibitory activity of different extractions of F. assa-foetida seed

\begin{tabular}{ll}
\hline Extracts & Percentage of DPP-IV inhibitory activity (\%) \\
\hline Ethanol & $24.533 \pm 1.080$ \\
Methanol & $14.346 \pm 1.080$ \\
Ethanol-methanol & $22.33 \pm 1.56$ \\
Aqueous & $12.322 \pm 0.838$ \\
\hline DPP-IV: Dipeptidyl peptidase IV, F. assafoetida: Ferula assafoetida
\end{tabular}

disease are some symptoms of T2DM in patients [31]. According to the International Diabetes Federation report, 425 million people are affected by diabetes worldwide; every 6 seconds one person dies from diabetes [3]

Up to now various medications have been produced and $\alpha$-glucosidase inhibition is one of these medications. By inhibiting $\alpha$-glucosidase, glucose levels in the blood can be returned to normal limits. Hence, the inhibitory activity of this digestive enzyme can be a good treatment for T2DM

The most recent medications used to treat T2DM are inhibitors of the DPP-IV enzyme. DPP-IV rapidly destroys the incretin hormones, GLP-1 and GIP. These peptides help the body produce more insulin when it is needed.

Synthetic oral hypoglycemic drugs are the most common form of treatment for T2DM, but they have undesirable side effects in patients with T2DM and also these drugs impose a high cost to patients. Therefore, research on medicinal plants as inexpensive resources containing valuable pharmaceutical metabolites is essential. F. assafoetida L. is an important medicinal plant belonging to the Apiaceae, traditionally used for the treatment of different diseases and recent pharmacological and biological studies have shown its anti-diabetic activities.

Considering the importance of identification of more efficient drugs with less side effects and also understanding the mechanism of action of hypoglycemic plants and since the antidiabetic activity of $F$ assa-foetida has not previously been investigated mechanistically, this study was done to investigate the $\alpha$-glucosidase and DPP-IV inhibitory activities of F. assa-fetida. In conclusion, the results of this study suggest that F. assafoetida through DPP-IV and $\alpha$-glucosidase inhibitory activities can be involved in the blood glucose control and could be recommended for the treatment of T2DM.

\section{ACKNOWLEDGMENT}

The authors would like to thank Farzaneh Aram and Mehdi Farahmandzadeh, staff at the Biotechnology Institute of the Shiraz University for their helps and support. This work was supported by grants from the University of Guilan.

\section{REFERENCES}

1. Ahrén B. DPP-4 inhibitors. Best Pract Res Clin Endocrinol Metab 2007;21(4):517-33.

2. Rosenthal MS. The Canadian Type 2 Diabetes Sourcebook. Canada: John Wiley \& Sons Canada, Ltd.; 2009. p. 34

3. International Diabetes Federation. IDF Diabetes Atlas. $7^{\text {th }}$ ed. Brussels, Belgium: International Diabetes Federation; 2015. Available from: http://www.diabetesatlas.org.

4. Brunetti L, Kalabalik J. Management of Type-2 diabetes mellitus in adults: Focus on individualizing non-insulin therapies. P T 2012;37(12):687-96

5. Inzucchi SE, Bergenstal RM, Buse JB, Diamant M, Ferrannini E, Nauck M, et al. Management of hyperglycemia in Type 2 diabetes: A patient-centered approach position statement of the American Diabetes Association (ADA) and the European Association for the Study of Diabetes (EASD). Diabetes Care 2012;35:1364-79.

6. Klein S, Sheard NF, Pi-Sunyer X, Daly A, Wylie-Rosett J, Kulkarni K, et al. Weight management through lifestyle modification for the prevention and management of Type 2 diabetes: Rationale and strategies a statement of the American Diabetes Association, the North American Association for the Study of Obesity, and the American Society for Clinical Nutrition. Diabetes Care 2004;27:2067-73.

7. Barnett A. DPP-4 inhibitors and their potential role in the management of Type 2 diabetes. Int J Clin Pract 2006;60(11):1454-70.

8. Richter B, Bandeira-Echtler E, Bergerhoff K, Lerch CL. Dipeptidyl peptidase-4 (DPP-4) inhibitors for Type 2 diabetes mellitus. Cochrane Database Syst Rev 2008;CD006739.

9. TiwariP. Recent trends in therapeutic approaches for diabetes management: A comprehensive update. J Diabetes Res 2015;2015:340838. 
10. van de Laar FA. Alpha-glucosidase inhibitors in the early treatment of Type 2 diabetes. Vasc Health Risk Manag 2008;4(6):1189-95.

11. van de Laar FA, Lucassen PL, Akkermans RP, van de Lisdonk EH, Rutten GE, van Weel C. Alpha-glucosidase inhibitors for patients with Type 2 diabetes: Results from a Cochrane systematic review and metaanalysis. Diabetes Care 2005;28(1):154-63.

12. Iranshahy $M$, Iranshahi $M$. Traditional uses, phytochemistry and pharmacology of asafoetida (Ferula assa-foetida oleo-gum-resin): A review. J Ethnopharmacol 2011;134(1):1-10.

13. Dehpour AA, Ebrahimzadeh MA, Fazel NS, Mohammad NS. Antioxidant activity of the methanol extract of Ferula assa-foetida and its essential oil composition. Grasas Aceites 2009;60:405-12.

14. Lee CL, Chiang LC, Cheng LH, Liaw CC, Abd El-Razek MH, Chang FR, et al. Influenza A (H1N1) antiviral and cytotoxic agents from Ferula assa-foetida. J Nat Prod 2009;72:1568-72.

15. Patil SD, Shinde S, Kandpile P, Jain AS. Evaluation of antimicrobial activity of asafoetida. Int J Pharm Sci Res 2015;6:722-7.

16. Fatehi M, Farifteh F, Fatehi-Hassanabad Z. Antispasmodic and hypotensive effects of Ferula assa-foetida gum extract. J Ethnopharmacol 2004:91(2-3):321-4

17. Yusufoglu HS, Soliman GA, Abdel-Rahman RF, Abdel-Kader MS, Ganaie MA, Bedir E, et al. Antihyperglycemic and antihyperlipidemic effects of Ferula assa-foetida and Ferula tenuissima extracts in diabetic rats. Pak J Biol Sci 2015;18:314-23.

18. Ooi KL, Muhammad TS, Tan ML, Sulaiman SF. Cytotoxic, apoptotic and anti- $\alpha$-glucosidase activities of 3, 4-di-O-caffeoyl quinic acid, an antioxidant isolated from the polyphenolic-rich extract of Elephantopus mollis Kunth. J Ethnopharmacol 2011;135(3):685-95.

19. Matheeussen V, Lambeir AM, Jungraithmayr W, Gomez N, Mc Entee K, van der Veken P, et al. Method comparison of dipeptidyl peptidase IV activity assays and their application in biological samples containing reversible inhibitors. Clin Chim Acta 2012;413(3-4):456-62

20. Iranshahi M, Alizadeh M. Antihyperglycemic effect of asafoetida (Ferula assa-foetida Oleo-Gum-Resin) in streptozotocin-induced diabetic rats. World Appl Sci J 2012;17:157-62.
21. Azari M, Mohiti-ardekani J, Abedini S, Mozayan MR. Effect of Ferula assa-foetida on cytoplasmic membrane glucose transporter isotype-4 of C2C12 cell line. Int J Med Lab 2014;1:46-53.

22. Hasimun P, Adnyana IK, Valentina R, Lisnasari E. Potential alphaglucosidase inhibitor from selected Zingiberaceae family. Asian J Pharm Clin Res 2016;9:164-7.

23. Pant G, Sai K, Babasaheb S, Reddy R, Sibi G. In vitro $\alpha$-amylase and $\alpha$-glucosidase inhibitor activities of Abutilon indicum leaves. Asian J Pharm Clin Res 2013;6:22-4.

24. Lee MK, Kim MJ, Cho SY, Park SA, Park KK, Jung UJ, et al. Hypoglycemic effect of Du-zhong (Eucommia ulmoides Oliv.) leaves in streptozotocin-induced diabetic rats. Diabetes Res Clin Pract 2005;67:22-8.

25. Sharma BR, Rhyu DY. Anti-diabetic effects of Caulerpa lentillifera: Stimulation of insulin secretion in pancreatic $\beta$-cells and enhancement of glucose uptake in adipocytes. Asian Pac J Trop Biomed 2014;4:575-80.

26. Yogisha S, Raveesha KA. Dipeptidyl peptidase IV inhibitory activity of Mangifera indica. J Nat Prod 2010;3:76-9.

27. Davis JA, Sharma S, Mittra S, Sujatha S, Kanaujia A, Shukla G, et al. Antihyperglycemic effect of Annona squamosa hexane extract in Type 2 diabetes animal model: PTP1B inhibition, a possible mechanism of action. Indian J Pharmacol 2012;44:326-32.

28. Purnomo Y, Soeatmadji DW, Sumitro SB, Widodo MA. Anti-diabetic potential of Urena lobata leaf extract through inhibition of dipeptidyl peptidase IV activity. Asian Pac J Trop Biomed 2015;5:645-9.

29. Lendeckel U, Arndt M, Wolke C, Reinhold D, Kähne T, Ansorge S. Inhibition of human leukocyte function, alanyl aminopeptidase (APN, CD13) and dipeptidylpeptidase IV (DP IV, CD26) enzymatic activities by aqueous extracts of Cistus incanus L. ssp. incanus. J Ethnopharmacol 2002;79:221-7.

30. Srivastava S, Koley TK, Singh SK, Tripathi YB. The tuber extract of Pueraria tuberosa Linn. Competitively inhibits DPP-IV activity in normoglycemic rats. Int J Pharm Pharm Sci 2015;15:227-31.

31. American Diabetes Association. 2. Classification and diagnosis of diabetes. Diabetes Care 2015;38 Suppl 1:8-16. 